\title{
Changing prevalence of asthma in school children: evidence for diagnostic changes in asthma in two surveys 13 yrs apart
}

\author{
W. Nystad*, P. Magnus*, A. Gulsvik**, I.J.K. Skarpaas+, K-H. Carlsen++
}

Changing prevalence of asthma in school children: evidence for diagnostic changes in asthma in two surveys 13 yrs apart. W. Nystad, P. Magnus, A. Gulsvik, I.J.K. Skarpaas, K-H. Carlsen. (CERS Journals Ltd 1997.

ABSTRACT: It is still unclear whether the reported increase in the prevalence of asthma is real or due to changes in diagnostic criteria. The objectives of this study were to compare the prevalence of diagnosed asthma with the prevalence of respiratory symptoms, and to compare the association between asthma and other atopic diseases in 1981 and 1994.

The study populations comprised randomly selected school classes in Oslo in $1981(n=1,772)$ and $1994(n=2,577)$. The main outcomes in these comparable crosssectional studies of children, 6-16 yrs of age, were parent-reported prevalence of diagnosed asthma, respiratory symptoms, eczema and hay fever. The questionnaire was identical in 1981 and 1994.

The response rates were $94 \%(1,674$ out of 1,772$)$ in 1981 and $85 \%(2,188$ out of 2,577 ) in 1994. The lifetime prevalence of asthma increased from $3.4 \%$ in 1981 to $9.3 \%$ in 1994; odds ratio (OR) 2.9 (95\% confidence interval (95\% CI) $2.1-4.0$ ) comparing 1994 to 1981 . The prevalence of occasional wheezing increased from 9.0 to $10.8 \%$; OR $1.2(95 \%$ CI 1.0-1.5), and attacks of wheezing from 3.7 to $6.8 \%$; OR 1.8 (95\% CI 1.3-2.5). Survival analyses for 3 year birth cohorts showed that asthma was more readily diagnosed in the latest birth cohort (1985-1988). The association between asthma and other atopic diseases decreased during the period under study.

The increase in diagnosed asthma and respiratory symptoms supports a true increase in asthma. However, the larger increase in diagnosed asthma than wheezing and a reduced association between asthma and other atopic diseases suggest that the increase in asthma may be explained, in part, by changes in diagnostic criteria.

Eur Respir J 1997; 10: 1046-1051.

\begin{abstract}
*Section of Epidemiology, Dept of Population Health Sciences, National Institute of Public Health, Oslo. **Dept of Thoracic Medicine, University Hospital Haukeland, Bergen. +Chest Clinic, Ullevål Hospital, Oslo. ${ }^{++}$Voksentoppen Centre of Asthma and Allergy, University Hospital, Oslo.
\end{abstract}

Correspondence: W. Nystad Section of Epidemiology

Dept of Population Health Sciences

National Institute of Public Health

Box 4404 Torshov

N-0403 Oslo

Norway

Keywords: Asthma

atopy

children

prevalence

questionnaire

Received: May 211996

Accepted after revision January 151997
There has been substantial interest in the increasing secular trends in the prevalence of childhood asthma [1-6]. Epidemiological data support an increase in asthma prevalence and morbidity, but the extent to which this change is exaggerated by diagnostic transfer and increased awareness of respiratory symptoms associated with wheezing illnesses is uncertain. Studies including objectively measured asthma-related parameters support a true increase $[3,5]$.

With increasing asthma morbidity, an increase in the occurrence of respiratory symptoms in the population is expected. The increase in the prevalence of physician-diagnosed asthma can, therefore, be compared to the increase in the prevalence of respiratory symptoms. Furthermore, if an increase in the prevalence of asthma is caused mainly by an increase in the occurrence of atopy, as has been claimed [7-9], the association between asthma and other atopic diseases ought to remain constant over time. In contrast, a change in the diagnostic criteria of asthma with a focus on obstructive respiratory symptoms without specific allergy, or a possible increase in factors that influence asthma but not other atopic diseases, ought to result in a reduced association to other atopic diseases.

The present study includes two samples of school children aged 6-16 yrs. The first sample was drawn from Oslo schools in 1981 [10], and the second from the same sampling frame in 1994.

The main objective was to compare secular trends in the prevalence of physician-diagnosed asthma with trends in respiratory symptoms. A second aim was to compare the association between asthma and other atopic diseases in 1981 and 1994.

\section{Subjects and method}

\section{Samples}

The target population was school children in the first to ninth grade in Oslo, aged 6-16 yrs. School classes were randomly selected from the current list of classes belonging to the municipality of Oslo. The 1981 study 
population included 1,772 children from 81 classes, representing 59 schools situated all over Oslo [10].

The 1994 sample comprised 118 classes, including 2,700 children representing 65 schools. Four classes did not participate because they were involved in other research projects. Five classes were excluded due to a majority of non-Norwegian ethnic groups among the children. Four of these classes were replaced by other classes at the same school where the majority of children were Norwegian. The study population was based on 113 classes, including 2,577 children, originating from 63 schools in the same geographical area as in 1981.

\section{Variables}

Questionnaires were distributed to the children at school, brought home to the parents for completion, and then returned to the teacher at school. The questionnaire was based on the children's questionnaire from the American Thoracic Society (ATS) [11], and the Medical Research Council (MRC) 1976 questionnaire on respiratory symptoms [12]. The questionnaire focused on asthma and respiratory symptoms, and included items about eczema and hay fever. The items defining each measure are listed in Appendix I. The questions used were identical in 1981 and 1994.

\section{Statistical analysis}

Lifetime and current prevalence rates were calculated. To compare prevalences, odds ratios (ORs) were estimated and Chi-squared tests were used. Treating the samples as historical cohorts, survival analyses using actuarial methods were conducted for 3 year birth cohorts, to estimate the probability of remaining free from asthma at different ages [13]. Cox regression was used in estimating the relative risk (RR) of asthma for each cohort [13]. In order to include the few children who were 6 and 16 yrs old in the samples, the youngest and oldest birth cohorts span 4 yrs. The length of follow-up is reflected in the age of the children when the survey was conducted. Logistic regression was used to estimate the association between asthma and other atopic diseases. The data from 1981 were recoded and reanalysed using the same methods as in 1994, which resulted in minor differences from data published previously [10]. A high proportion of missing values occurred for the following items in 1981: asthma (9\%), eczema (16\%) and hay fever $(18 \%)$. In contrast, there were few missing data for these items in 1994: asthma (0.5\%), hay fever $(0.5 \%)$ and eczema $(<0.5 \%)$. Missing data were excluded. All data were analysed using the Statistical Products and Service Solutions package (SPSS) for Windows (Release 6.0). A p-value of less than 0.05 was considered statistically significant.

\section{Results}

The response rates were $94 \%(1,674$ out of 1,772$)$ in 1981 and $85 \%(2,188$ out of 2,577$)$ in 1994 . The mean age was 11.0 yrs (SD, 2.6) in 1981 and 10.6 yrs (SD 2.4) in 1994 , and the proportion of boys was $50 \%$ ( 841 out of 1674$)$ in 1981 and $52 \%(1,128$ out of 2,188$)$ in 1994.

\section{Asthma}

From 1981 to 1994, the lifetime prevalence of physician-diagnosed asthma increased from 3.4 to $9.3 \%$. As seen in table 1, the OR for lifetime asthma in 1994 compared to 1981 was 2.9 (95\% confidence interval $(95 \%$ CI) 2.1-4.0). The male/female gender ratio for lifetime prevalence of asthma was 2.0 in 1981 and 1.4 in 1994, and for current asthma 3.5 and 1.6, respectively (not tabulated). The use of asthma drugs increased from 1.1 to $4.7 \%$; OR 3.9 (95\% CI 2.3-6.6).

The 1981 study population was divided into three cohorts based on the following birth years: 1964-1967, 1968-1970 and 1971-1974. The 1994 study population was divided into three cohorts as follows: 19781981, 1982-1984 and 1985-1988. The probability of not

Table 1. - Lifetime prevalence of physician-diagnosed asthma and prevalence of current asthma and respiratory symptoms, such as attacks of breathlessness and wheezing caused by exposure to pollen, animals and physical activity in school children in 1981 and 1994, with odds ratios (ORs) comparing 1994 to 1981

\begin{tabular}{|c|c|c|c|c|c|c|}
\hline & \multicolumn{2}{|c|}{1981} & \multicolumn{2}{|c|}{1994} & \multirow[b]{2}{*}{ OR } & \multirow[b]{2}{*}{$95 \% \mathrm{C}$} \\
\hline & $\underset{n}{\text { Sample }}$ & $\underset{\%}{\text { Symptoms }}$ & $\underset{n}{\text { Sample }}$ & $\underset{\%}{\text { Symptoms }}$ & & \\
\hline $\begin{array}{l}\text { Lifetime prevalence of } \\
\text { asthma }\end{array}$ & 1529 & 3.4 & 2179 & 9.3 & 2.9 & $(2.1-4.0)$ \\
\hline Current asthma & 1529 & 1.6 & 2179 & 5.5 & 3.3 & $(2.1-5.1)$ \\
\hline Use of asthma drugs & 1529 & 1.1 & 2179 & 4.7 & 3.9 & $(2.3-6.6)$ \\
\hline Occasional wheezing & 1611 & 9.0 & 2167 & 10.8 & 1.2 & $(1.0-1.5)$ \\
\hline Attacks of wheezing & 1636 & 3.7 & 2175 & 6.8 & 1.8 & $(1.3-2.5)$ \\
\hline $\begin{array}{l}\text { Occasional wheezing and attacks } \\
\text { Wheezing on exposure }\end{array}$ & 1611 & 2.2 & 2164 & 4.2 & 2.0 & $(1.4-3.1)$ \\
\hline to pollen & 1573 & 4.8 & 2096 & 7.3 & 1.5 & $(1.2-2.0)$ \\
\hline $\begin{array}{l}\text { Wheezing on exposure } \\
\text { to animals }\end{array}$ & 1568 & 3.3 & 2064 & 4.4 & 1.3 & $(0.9-1.9)$ \\
\hline $\begin{array}{l}\text { Wheezing caused by } \\
\text { physical activity }\end{array}$ & 1579 & 5.8 & 2102 & 11.2 & 2.0 & $(1.6-2.6)$ \\
\hline
\end{tabular}

95\% CI: 95\% confidence interval. 


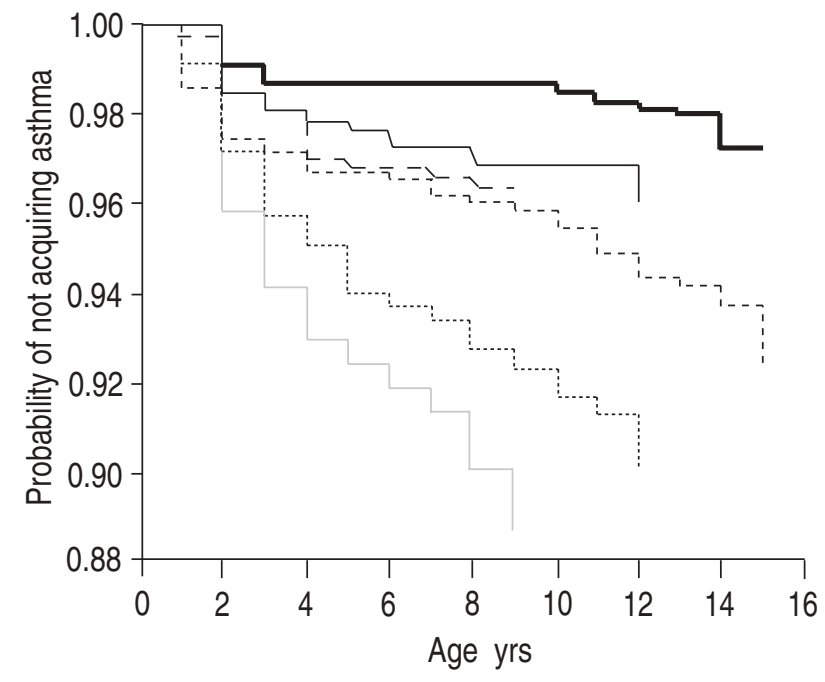

Fig. 1. - The probability of not being diagnosed with asthma at any age (0-16 yrs) for six different cohorts of children; _ :1964-1967 $(\mathrm{n}=518) ; \ldots$ :1968-1970 ( $\mathrm{n}=505) ;---: 1971-1974(\mathrm{n}=498)$; --.-- : 1978-1981 (n=549); ------ :1982-1984 (n=845); — : 1985-1988 $(\mathrm{n}=786)$.

having received a diagnosis of asthma at different ages in these cohorts are presented in figure 1. The risk of asthma increased for each cohort compared to the reference group (1964-1967 cohort). The RRs increased from 1.8 (95\% CI 0.9-3.8) for children born 1968-1970 to 6.4 (95\% CI 3.5-11.7) for children born 1985-1988. The RR was 2.5 (95\% CI 1.2-5.2) for children born 1971-1974, 2.1 (95\% CI 1.1-4.0) for children born 1978-1981, and 4.4 (95\% CI 2.4-8.1) for children born 1982-1984. Figure 1 shows that asthma is more readily diagnosed before 2 yrs of age and continuously throughout childhood in the latest cohort.

\section{Wheezing}

As shown in table 1: the prevalence of occasional wheezing increased from $9.0 \%$ in 1981 to $10.8 \%$ in 1994, OR 1.2 (95\% CI 1.0-1.5); attacks of wheezing during the last 3 yrs increased from 3.7 to $6.8 \%$, OR 1.8 (95\% CI 1.3-2.5); and the combination of occasional wheezing and attacks of wheezing increased almost twofold, OR 2.0 (95\% CI 1.4-3.1). Physical activity was the factor most commonly reported to provoke wheezing, with an increased prevalence from $5.8 \%$ in 1981 to $11.2 \%$ in 1994, OR 2.0 (95\% CI 1.6-2.6).

The proportion of children with occasional wheezing who were diagnosed with current asthma was $17 \%$ (25 out of 144) in 1981 and $39 \%$ (91 out of 234) in 1994 $(\mathrm{p}<0.001)$. The prevalence of current asthma among subjects reporting attacks of wheezing was 33\% (20 out of 61 ) in 1981 and $49 \%$ (73 out of 148) in $1994(\mathrm{p}=0.03)$. The prevalence of occasional wheezing in children with current asthma was 93\% (25 out of 27) in 1981 versus $79 \%$ (95 out of 120) in 1994, and did not differ significantly $(\mathrm{p}=0.1)$. Similar results were found for attacks of wheezing, 74\% (20 out of 27) in 1981 compared to $61 \%$ (73 out of 120) in $1994(\mathrm{p}=0.3)$. Among nonasthmatics, $8 \%$ (119 out of 1,504) reported wheezing in 1981 versus $3 \%(65$ out of 2,088$)$ in $1994(\mathrm{p}<0.001)$ (not tabulated).
Table 2. - Lifetime prevalence of eczema and hay fever in boys and girls in 1981 and 1994, and odds ratios (ORs) comparing 1994 to 1981

\begin{tabular}{|c|c|c|c|c|c|c|}
\hline & \multicolumn{2}{|c|}{1981} & \multicolumn{2}{|c|}{1994} & \multirow[b]{2}{*}{ OR } & \multirow[b]{2}{*}{$95 \% \mathrm{CI}$} \\
\hline & $\underset{\mathrm{n}}{\text { Sample }}$ & Sym & $\underset{\mathrm{n}}{\text { Sample }}$ & $\begin{array}{c}\text { Sym } \\
\%\end{array}$ & & \\
\hline Boys & & & & & & \\
\hline Eczema & 696 & 9.2 & 1128 & 15.4 & 1.8 & $(1.3-2.5)$ \\
\hline $\begin{array}{l}\text { Hay fever } \\
\text { Girls }\end{array}$ & 683 & 7.3 & 1128 & 9.9 & 1.4 & $(1.0-2.0)$ \\
\hline Eczema & 703 & 10.2 & 1059 & 18.9 & 2.0 & $(1.5-2.8)$ \\
\hline $\begin{array}{l}\text { Hay fever } \\
\text { Total }\end{array}$ & 690 & 5.9 & 1059 & 5.5 & 0.9 & $(0.6-1.4)$ \\
\hline Eczema & 1399 & 9.7 & 2187 & 17.1 & 1.9 & $(1.6-2.4)$ \\
\hline Hay fever & 1373 & 6.6 & 2187 & 7.8 & 1.2 & $(1.0-1.6)$ \\
\hline
\end{tabular}

95\% CI: 95\% confidence interval; Sym: symptoms.

\section{Other atopic diseases}

The lifetime prevalence of eczema and hay fever, and ORs comparing 1994 to 1981 are presented in table 2. Eczema increased from $9.7 \%$ in 1981 to $17.1 \%$ in 1994 , OR 1.9 ( $95 \%$ CI 1.6-2.4), and hay fever from 6.6 to $7.8 \%$, OR 1.2 (95\% CI 1.0-1.6). In contrast, the prevalence of hay fever among children with asthma decreased

Table 3. - Odds ratios (ORs) for lifetime physiciandiagnosed asthma according to gender, age, presence of eczema and hay fever in 1981 and 1994

\begin{tabular}{|c|c|c|c|c|c|}
\hline & Asth & Ima & Sample & COR & AOR \\
\hline & Yes & No & & $(95 \%$ CI $)$ & $(95 \%$ CI $)$ \\
\hline & & & $\mathrm{n}$ & & \\
\hline 1981 & & & & & \\
\hline Gender & & & & & \\
\hline Girl & 2 & 98 & 766 & 1.0 & 1.0 \\
\hline Boy & 4 & 96 & 763 & $2.0(1.1-3.6)$ & $1.8(0.9-3.7)$ \\
\hline Age & & & & & \\
\hline $7-9$ yrs & 4 & 96 & 499 & 1.0 & 1.0 \\
\hline $10-12$ yrs & s 4 & 96 & 506 & $0.9(0.4-1.8)$ & $0.8(0.4-1.9)$ \\
\hline $13-15$ yrs & 3 & 97 & 518 & $0.7(0.3-1.4)$ & $0.5(0.2-1.3)$ \\
\hline Eczema & & & & & \\
\hline No & 2 & 98 & 1203 & 1.0 & 1.0 \\
\hline Yes & 12 & 88 & 127 & $5.6(2.8-11.3)$ & $2.8(1.1-7.2)$ \\
\hline Hay fever & & & & & \\
\hline No & 2 & 98 & 1219 & 1.0 & 1.0 \\
\hline Yes & 14 & 86 & 86 & $7.2(3.3-15.5)$ & $6.6(2.6-16.4)$ \\
\hline 1994 & & & & & \\
\hline Gender & & & & & \\
\hline Girl & 8 & 92 & 1056 & 1.0 & 1.0 \\
\hline Boy & 11 & 89 & 1123 & $1.4(1.1-1.9)$ & $1.4(1.1-1.9)$ \\
\hline Age & & & & & \\
\hline 7-9 yrs & 11 & 89 & 786 & 1.0 & 1.0 \\
\hline $10-12$ yrs & s 9 & 91 & 845 & $0.9(0.6-1.2)$ & $0.9(0.6-1.2)$ \\
\hline $13-15$ yrs & s 7 & 93 & 549 & $0.6(0.4-0.9)$ & $0.6(0.4-0.9)$ \\
\hline Eczema & & & & & \\
\hline No & 8 & 92 & 1807 & 1.0 & 1.0 \\
\hline Yes & 16 & 84 & 373 & $2.5(1.8-3.5)$ & $2.0(1.4-2.8)$ \\
\hline Hay fever & & & & & \\
\hline No & 8 & 92 & 2010 & 1.0 & 1.0 \\
\hline Yes & 18 & 81 & 170 & $2.7(1.7-4.2)$ & $1.9(1.3-3.0)$ \\
\hline
\end{tabular}

COR: crude odds ratio; AOR: adjusted odds ratio; $95 \% \mathrm{CI}$ : $95 \%$ confidence interval. 
from $30.8 \%$ in 1981 to $15.3 \%$ in 1994 , OR $2.5(95 \%$ CI 1.2-5.5) comparing 1981 to 1994 , while the prevalence of eczema among asthmatics did not change significantly comparing the two surveys: $198134.9 \%$ and 1994 29.2\%, OR 1.3 (95\% CI 0.7-2.6) (not tabulated).

\section{Multivariate analysis}

The ORs for asthma by gender, age and presence of hay fever and eczema are presented in table 3. The association between asthma and hay fever decreased from an AOR of $6.6(95 \%$ CI 2.6-16.4) in 1981 to $1.9(95 \%$ CI 1.3-3.0) in 1994, while the association between asthma and eczema was an AOR of 2.8 (95\% CI 1.1-7.2) in 1981 and 2.0 (95\% CI 1.4-2.8) in 1994 (table 3).

Exclusion of the few non-Norwegian children in 1994 $(n=274)$ did not influence the main trends of the results. Compared with Norwegians, non-Norwegians tended to report less asthma, respiratory symptoms and other atopic diseases: asthma $6.6 \%$ (18 out of 273), occasional wheezing $7.4 \%$ (20 out of 271 ), eczema $10.6 \%$ (29 out of 274 ), hay fever $4.4 \%$ (12 out of 274 ).

\section{Discussion}

The present study of two cross-sectional samples 13 yrs apart showed a larger increase in physician-diagnosed asthma than respiratory symptoms. Asthma was more readily diagnosed before 2 years of age and through childhood in the latest birth cohorts in the 1994 sample. The degree of association between asthma and other atopic diseases decreased from the first to the second survey.

Before discussing the implications of the findings, several methodological aspects need to be considered. Due to a moderate-to-high response rate, selection bias is unlikely. The nonrespondents in 1994 represent a few children in several classes situated all over Oslo. Subjects with respiratory symptoms tend to be early respondents [14]. If the $10 \%$ difference in response rate represented subjects without asthma and respiratory symptoms, it would result in an approximately $1 \%$ decrease in the prevalence of physician-diagnosed asthma and respiratory symptoms in 1994. Others have not reported any difference in the prevalence of asthma between the responses to questionnaires in groups of late respondents and early respondents [8].

The difference between the two samples in the proportion of incomplete questionnaires in 1981 and 1994 may influence the results. The questionnaires were more extensively completed in 1994 than 1981. This suggests an increased awareness of asthma, wheezing and other atopic diseases from the first to the second survey.

The finding of a larger increase in diagnosed asthma than in occasional wheezing may be influenced by nonillness related factors. The lower prevalence of diagnosed asthma compared to wheezing in 1981 suggests underdiagnosis in that period. This suggestion is supported by a larger proportion of children with occasional wheeze and attacks of wheezing who have received a diagnosis of current asthma in 1994, and by a reduction in the prevalence of wheezing among nonasthmatics from 1981 to 1994 . The findings are consistent with an improvement in diagnosis of asthma from the first to the second survey.

The present study shows, in agreement with other repeated cross-sectional studies, a smaller relative increase in wheezing than in asthma [2-4, 15]. There is a tendency for studies from the UK with the earliest baseline year, $(<1975)[2,3,16]$ to report a larger relative increase in wheezing than those with later baseline years of study, (>1980) [4, 15]. As in the present study, the prevalence ratio between asthma and wheezing is close to one in the study with the latest baseline year (1985) of study [15]. ANDERSON [17] suggested that the increase in asthma reached a plateau in the mid-1980s [17]. A study performed in 1994 suggested, however, that the prevalence of childhood wheeze was still increasing, at least in Aberdeen [8]. These studies are, however, all based on questionnaires, where it is uncertain to what extent the changes represent a true increase in asthma, increased awareness, or diagnostic transfer.

Few studies have included objectively measured asthma-related parameters. In an Australian study, the increase in bronchial hyperresponsiveness occurred only in atopic subjects, and there was no increase in atopy as measured by skin-prick test [5]. BuRR et al. [3] reported an increase in exercise-induced bronchoconstriction (EIB) using free running, which was not standardized concerning exercise intensity. Increased EIB in asymptomatic children may also not be a strong predictor for subsequent development of symptomatic asthma [18]. Thus, these few reports of repeated objective measurements are inconsistent.

The present study is consistent with other studies in showing that physical activity is an important provoking factor for wheezing $[3,4,6]$. An objective test of EIB is recognized by others as a specific measure of asthma $[19,20]$. Thus, an increase in exercise induced wheezing may suggest a real increase in asthma morbidity if the exposure is equally common over time.

Of particular interest is the finding of a cohort effect in diagnosing asthma. Children in the two latest birth cohorts (1982-1984 and 1985-1988) were more readily given the diagnosis of asthma at an early age and throughout childhood. During the same period, the definition of asthma has changed in Norway [21]. In general, concerns arise regarding the validity and reliability with the use of retrospective parental reports. The purpose of this study was to compare two similar samples of school children, and the issues of recall bias that are more pertinent here are whether factors differentially affect parental reports, firstly, between samples, and, secondly, between cohorts. There is no a priori reason to believe that parental reporting per se would vary between samples. A recall bias within samples would occur if the parents of the oldest children had forgotten some of their asthma events. The classification of disease in this study was not based on an operational definition of symptoms, but rather on physician-diagnosed asthma. This is remarkably specific, in that people who claim to have a certain lung disease nearly always seem to have it [22].

The finding of a reduction in the association between asthma and other atopic diseases in 1994 compared with 1981 is consistent with changes in diagnostic criteria. The diagnosis of asthma in the latter period may be influenced by factors other than atopic conditions of the 
child. In contrast with OMran and Russel [8], we do not suggest that the explanation for the increasing prevalence of asthma is explained by the increasing prevalence of other atopic disorders. The small increase in hay fever in the present study is consistent with the suggestion that the increase in asthma is not explained by an increase in atopy alone. The finding that the prevalence of hay fever decreased in children with asthma from 1981 to 1994 supports this hypothesis. In addition, the male/female gender ratio in 1981 was more similar to that for atopy shown in other studies [23]. Our findings do not exclude that there may have been a separate increase in bronchial hyperresponsiveness in the general population.

The children in the 1981 sample were born between 1964 and 1974, whilst those in the second sample were born from 1978 to 1988 . In 1960, the ATS recommended a clinical definition of asthma, stating that the host defect associated with asthma is related to altered immunological response as in atopy [24]. In order to include and treat children with respiratory disorders, the definition of infantile asthma was extended to include episodes of wheezing in 1975 [25], and in 1981 it was proposed that any infant with recurrent episodes of wheezing, three or more attacks, should be considered as having asthma, regardless of age of onset, evidence of atopy, apparent precipitating cause of wheeze, or frequency of the wheeze [7]. In Norway, the definition of asthma as three or more episodes of bronchial obstruction was used for childhood asthma from the early 1980s [21]. The change in diagnostic criteria was supported by the focus on underdiagnosis and undertreatment of childhood asthma that took place during the 1980s [26]. The asthma population probably consists of different subgroups [27]. In the present study, there is a decrease in the proportion of asthmatic subjects reporting asthma together with other atopic diseases.

If the increase in the prevalence of physician-diagnosed asthma reflects a true increase in asthma morbidity alone, possible causes remain a question of speculation. This study was not designed to elucidate factors that may cause changes.

In conclusion, an increase in diagnosed asthma and respiratory symptoms supports a true increase in asthma. However, a disproportionate increase in diagnosed asthma and respiratory symptoms supported by a reduced association between asthma and other atopic diseases suggests that the increase in asthma may be explained, in part, by changes in diagnostic criteria.

\section{Appendix I}

The outcomes were defined as follows:

Lifetime prevalence of asthma. "Has the child been treated by a doctor or admitted to hospital for asthma?" If "Yes", "Age of onset?"

Current asthma. "Does the child still have asthma?" If "No", "Age where the informant was free from asthma?"

Use of asthma drugs. "Does the child currently take medicine for asthma?"
Occasional wheezing. "Does the child's chest ever sound whistly?"

Attacks of wheezing. "During the last 3 yrs, has the child had an attack of wheezing at rest without having a cold?"

Current wheezing caused by exposure to pollen, animals and physical activity. "Do any of the following cause whistling in the chest or wheezing:

a) newly cut grass, flowers or trees?

b) animals?

c) running or other physical activities?"

Other diseases associated with atopy. "Has the child been treated by a doctor or admitted to hospital because of: a) eczema? b) hay fever?"

Acknowledgements: The authors thank the Norwegian Research Council, and the Norwegian Asthma and Allergy Society for help with funding and $\AA$. Andersen (Norwegian Cancer Register) for providing the data from 1981 .

\section{References}

1. Yunginger JW, Reed CE, O'Conell EJ, Melton JL, O'Fallon MW, Silverstein MDA. Community-based study of the epidemiology of asthma. Am Rev Respir Dis 1992; 146: 888-894.

2. Burney PG, Chinn S, Rona RJ. Has the prevalence of asthma increased in children? Evidence from the national study of health and growth 1973-1986. BMJ 1990; 300: 1306-1310.

3. Burr ML, Butland BK, King S, Vaughan-Williams E. Changes in asthma prevalence: two surveys 15 years apart. Arch Dis Child 1989; 64: 1452-1456.

4. Anderson HR, Butland BK, Strachan DP. Trends in prevalence and severity of chilhood asthma. BMJ 1994; 308: 1600-1604.

5. Peat J, van den Berg R, Green WF, Mellis C, Leeder $\mathrm{S}$, Woolcock A. Changing prevalence of asthma in Australian children. BMJ 1994; 308: 1591-1596.

6. Robertson C, Heycock E, Nolan T, Olinsky A, Phelan P. Prevalence of asthma in Melbourne schoolchildren: changes over 26 years. BMJ 1991; 302: 1116-1118.

7. Tabachnic E, Levison H. Infantile bronchial asthma. $J$ Allergy Clin Immunol 1981; 67(5): 339-347.

8. Omran M, Russel G. Continuing increase in respiratory symptoms and atopy in Aberdeen schoolchildren. BMJ 1996; 34: 312.

9. Nicolai T, von Mutius E. Respiratory hypersensitivity and environmental factors: East and West Germany. Toxicol Lett 1996; 86: 105-113.

10. Skarpaas IJK, Gulsvik A. Prevalence of bronchial asthma and respiratory symptoms in schoolchildren in Oslo. Allergy 1985; 40: 295-299.

11. British Medical Research Council. Recommended respiratory disease questionnaires for use with adults and children in epidemiological research. London, England, British Medical Research Council, 1978; p7.

12. Medical Research Council. Questionnaire on respiratory symptoms. 20 Park Crescent, London WIN4 Al. Publication Group, Medical Research Council, 1976.

13. Altman DG. In: Practical Statistics for Medical Research. London, Chapman \& Hall, 1992; Chapter 13, Analysis of Survival Times. pp. 325-395. 
14. Bakke $\mathrm{P}$, Gulsvik A, Lilleng $\mathrm{P}$, Overå O, Hanoa R, Eide E. Postal survey on airborne occupational exposure and respiratory disorders in Norway: causes and consequences of nonresponse. J Epidemiol Commun Health 1990; (44): 316-320.

15. Hill R, Williams J, Tattersfield A, Britton J. Changes in use of asthma as a diagnostic label for wheezing illness in schoolchildren. $\mathrm{Br}$ Med $J$ 1989; 299: 898.

16. Ninan T, Russel G. Respiratory symptoms and atopy in Aberdeen schoolchildren: evidence from two surveys 25 years apart. BMJ 1992; 304: 873-875.

17. Anderson $\mathrm{H}$. Is asthma really increasing? Paediatr Respir Med 1993; 1: 6-10.

18. Ulrik C, Backer V. Increased bronchial responsiveness to exercise as a risk factor for symptomatic asthma: findings from a longitudinal population study of children and adolescents. Eur Respir J 1996; 9: 1696-1700.

19. Godfrey S, Springer C, Noviski N, Maayan C, Avital A. Exercise but not methacholine differentiates asthma from chronic lung disease in children. Thorax 1991; 46: 488-492.

20. Avital A, Springer C, Bar Yishay E, Godfrey S. Adenosine, methacholine and exercise challenges in children with asthma or paediatric chronic obstructive pulmonary disease. Thorax 1995; 50: 511-516.

21. Carlsen KH, Ørstavik I, Leegaard J, Høeg H. Respiratory virus infections and aeroallergens in acute bronchial asthma. Arch Dis Child 1984; 59: 310-315.

22. Burney P, Laitinen L, Perdrizet S, et al. Validity and repeatability of the IUATLD (1984) bronchial symptoms questionnaire: an international comparison. Eur Respir J 1989; 2: 940-945.

23. Sears MR, Burrows B, Flannery EM, Herbison GP, Holdaway MD. Atopy in childhood. I. Gender and allergen-related risks for development of hay fever and asthma. Clin Exp Allergy 1993; 23: 941-948.

24. American Thoracic Society. Definitions and classifications of chronic bronchitis, asthma and pulmonary emphysema. Am Rev Respir Dis 1962; 85: 762-768.

25. Brascher GW. Clinical aspects of infantile asthma. Ann Allergy 1975; 35: 216-220.

26. Speight ANP, Lee DA, Hey EN. Underdiagnosis and undertreatment of asthma in childhood. Br Med J 1983; 286: $1253-1256$.

27. Aas K. Heterogeneity of bronchial asthma: subpopulations or different stages of the disease. Allergy 1981; 36: 3-14. 